\title{
Incidence and Nature of Lower-Limb Deep Vein Thrombosis in Patients with Polytrauma on Thromboprophylaxis: A Prospective Cohort Study
}

\author{
Sharfuddin Chowdhury $\mathbb{D}^{1}$ \\ Fatmah Alrawaji iD ${ }^{2}$ \\ Luke PH Leenen (iD ${ }^{3}$ \\ 'Trauma Center, King Saud Medical City, \\ Riyadh, Saudi Arabia; ${ }^{2}$ Department of \\ General Surgery, King Saud Medical City, \\ Riyadh, Saudi Arabia; ${ }^{3}$ Department of \\ Trauma, University Medical Center \\ Utrecht, Utrecht, Netherlands
}

Purpose: Deep vein thrombosis (DVT) is common among the severely injured and may lead to pulmonary embolism (PE), which can be life threatening. Thromboprophylaxis may reduce the incidence of venous thromboembolism (VTE); it does not guarantee complete protection. This study's primary aim was to determine the incidence and nature of lower-limb DVT in polytrauma patients taking prophylaxis. The secondary objective was to assess the incidence of DVT-related complications, including the development of PE and death.

Patients and Methods: This prospective observational study included patients age 18 years or older who presented with polytrauma directly from the scene and were admitted into the trauma unit between March 1, 2020 and August 31, 2020. All patients underwent lowerlimb ultrasound during their hospital course to diagnose DVT.

Results: A total of 169 patients underwent extremity Doppler ultrasound to detect DVT. Of these, 69 patients $(40.8 \%)$ were considered at the highest-risk for VTE development. For VTE prophylaxis, 115 patients $(68 \%)$ received pharmacologic agents, and 54 patients $(32 \%)$ had intermittent pneumatic compression on admission. Three patients $(1.8 \%)$ developed DVT despite prophylaxis. Four patients (2.4\%) developed PE during the index presentation and were diagnosed between days 3 and 13 after injury. Early DVT was not detected in any patients with diagnosed PE. Overall, nine patients (5.33\%) died, but no in-hospital deaths were related to DVT and/or PE.

Conclusion: The incidence of DVT in polytrauma patients remains low in our small series, perhaps because of the mandatory VTE risk assessment for all hospitalized patients and the early initiation of prophylaxis. Using a trauma center registry to measure DVT and PE incidence regularly is recommended to improve trauma care quality.

Keywords: venous thromboembolism, deep vein thrombosis, pulmonary embolism, wounds and injuries, doppler ultrasonography, heparin

\section{Introduction}

Deep vein thrombosis (DVT), a common type of venous thrombosis, and its complication, pulmonary embolism (PE), can be life threatening. In the United States, 187,000 people age 45 years or older are newly diagnosed with venous thromboembolism (VTE) each year. ${ }^{1}$ The annual incidence of VTE ranges from 1.69 to 1.98 per 1000 in the general population, including annual DVT and PE incidences of 1.24 and 0.6 per 1000 per year, respectively. ${ }^{2}$ After a trauma, the incidence of VTE varies from $7 \%$ to $58 \%$, depending on patient demographics, mechanism of injury, diagnoses, and type of VTE prophylaxis used. ${ }^{3}$ The
Correspondence: Sharfuddin Chowdhury Trauma Center, King Saud Medical City, Riyadh, Saudi Arabia

Tel +966 I I-435-5555 (Ext. I385)

Fax +966 II -435-4406

Email dr_smahmud@yahoo.com 
association between trauma, particularly lower-extremity fractures, and VTE has been recognized for almost a century. Several autopsy studies have confirmed the relationship between injury and VTE, even when VTE was not diagnosed premortem. ${ }^{4,5}$ In 1967, Freeark et al ${ }^{6}$ demonstrated with a venogram that $35 \%$ of patients with fractures develop venous thrombosis. The asymptomatic thrombus formation was observed within $24 \mathrm{~h}$ of injury, both in the injured and the uninjured limbs. ${ }^{6}$

The endothelial injury, stasis of blood flow, and hypercoagulability known as Virchow's triad plays an essential role in thrombus formation. Notably, severe trauma often precipitates one or all of these risk factors, which increases the risk of VTE. ${ }^{7}$ Intimal damage caused by direct injury to the vessels leads to thrombosis. Prolonged bed rest, immobilization, hypoperfusion, and paralysis caused by trauma promote venous stasis. ${ }^{8}$ Most trauma patients are also in a hypercoagulable state at admission. The rate of DVT doubles in such patients despite prophylaxis. ${ }^{9}$ Severe trauma also activates the prothrombotic state, which contributes to thrombus formation. ${ }^{10}$

Using different types of VTE prophylaxis - mechanical or pharmacologic - for trauma patients is currently the standard practice. Early commencement of VTE prophylaxis may not be possible in high-risk multi-trauma patients. Examples of these high-risk situations include lower limb fractures with plaster, severe head trauma, high-grade abdominal organ injury, or excessive bleeding. For patients with high-risk major trauma, the American College of Chest Physicians (ACCP) recommends mechanical prophylaxis, preferably with intermittent pneumatic compression (IPC), when not contraindicated by lower-extremity injury. They suggest adding pharmacologic prophylaxis, such as low-molecular-weight heparin (LMWH) or unfractionated heparin (UFH), when the risk of bleeding diminishes or the contraindication to heparin resolves (grade 2C). They discourage periodic surveillance with venous compression ultrasound or insertion of an inferior vena cava (IVC) filter for the primary prevention of VTE (grade 2C). They also recommend continuing the VTE prevention in the hospital until patients are ambulatory. Patients who undergo major orthopedic surgery may need extended thromboprophylaxis in the outpatient period for up to 35 days after the day of surgery (grade 2B). In chronically immobilized persons residing at home or in a nursing home, the ACCP guidelines suggest against the routine use of thromboprophylaxis (grade 2C). ${ }^{11}$
This study's primary aim was to determine the incidence and nature of lower-limb DVT in polytrauma patients on VTE prophylaxis. The secondary objective was to assess DVT-related complications, including the development of PE or death.

\section{Patients and Methods Settings}

King Saud Medical City (KSMC) is a tertiary care center with a capacity of 1400 inpatients beds. A dedicated trauma unit manages all patients admitted for polytrauma. ${ }^{12}$ The trauma unit admits 50-70 patients with polytrauma per month. According to the hospital policy, all patients must have a VTE risk assessment before admission to the hospital and must start VTE prophylaxis according to the recommendation unless otherwise contraindicated. The attending physician fills out the VTE risk assessment form electronically in the hospital information system (Medisys).

\section{Design}

This prospective, observational study included patients age 18 years or older presenting with polytrauma directly from the scene and admitted to the trauma unit between March 01, 2020, and August 31, 2020. The study excluded patients transferred from another facility, because they spent a variable period before transfer to KSMC and had an unknown prophylaxis status. Also, non-Saudi patients without insurance coverage who could not pay the additional cost associated with ultrasounds or who did not consent to the procedure were excluded from the study.

\section{VTE Risk Assessment Tool}

An expert panel led by the Saudi Association for Venous Thromboembolism (a subsidiary of the Saudi Thoracic Society), with methodological guidance from the McMaster University Guideline Working Group, adopted a VTE risk assessment tool from a validated Caprini risk assessment model and developed a clinical practice guideline to assist healthcare providers in VTE prevention as part of a Saudi Ministry of Health initiative to improve medical practices in the Kingdom (Figure 1). ${ }^{13}$ Using this evaluation and the VTE risk scores, the patients were classified as having a low risk (risk score, 0-2), a moderate- to high- risk (risk score, 3-6), or the highest-risk (risk score $\geq 7$ ) for VTE (Figure 1). 


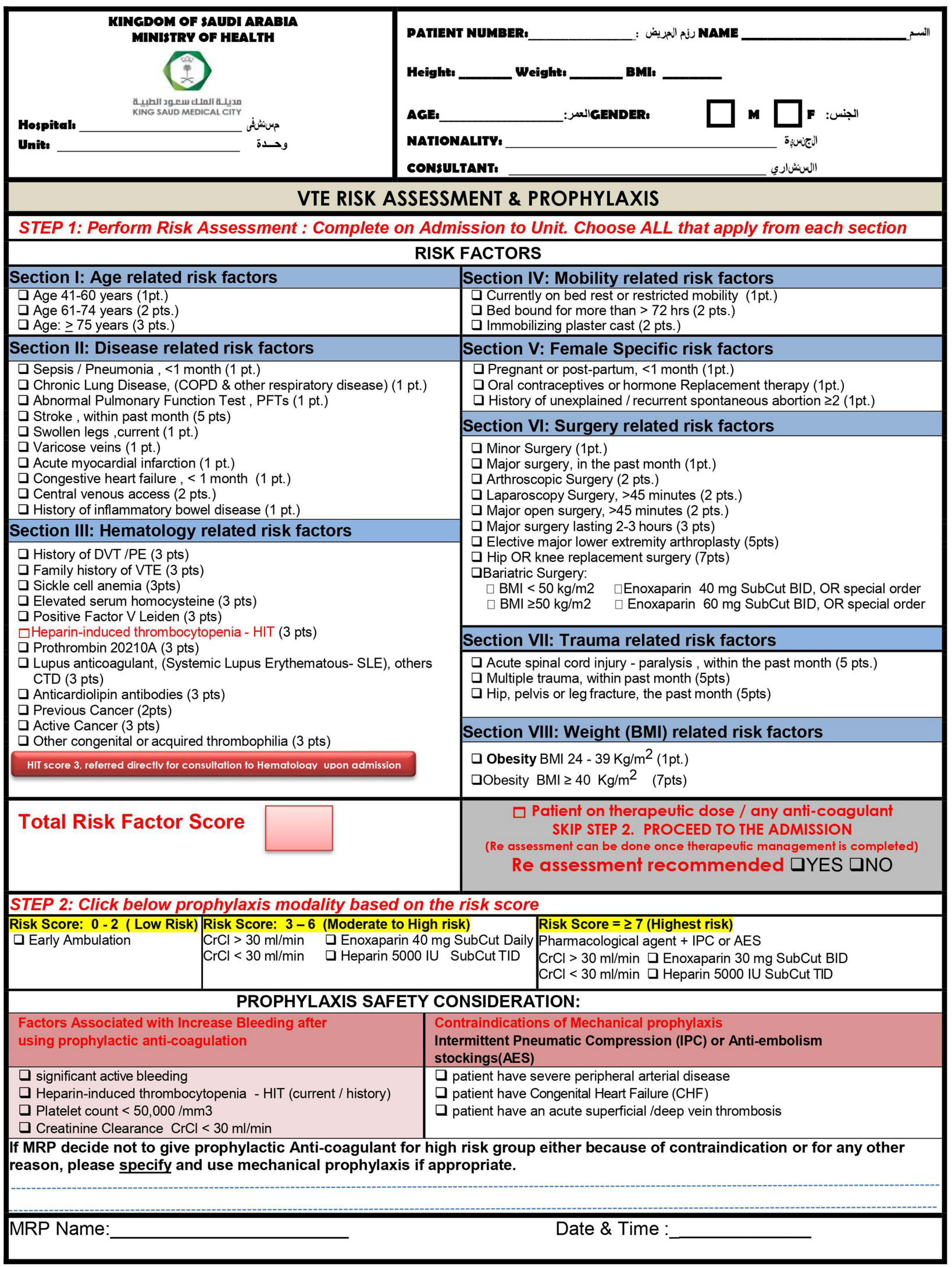

Figure I VTE risk assessment and prophylaxis. 


\section{VTE Prophylaxis}

Pharmacologic prophylaxis was prescribed for all patients as per the recommendation of the VTE risk assessment tool immediately on admission. Patients with moderate- to high-risk received enoxaparin $40 \mathrm{mg}$ subcutaneously daily. Patients in the highest-risk group received enoxaparin doses of $30 \mathrm{mg}$ twice daily in addition to IPC. When the patient's creatinine clearance was $<30 \mathrm{~mL} / \mathrm{min}$ or when enoxaparin was contraindicated (eg, pregnancy), the patient received 5000 IU of UFH subcutaneously three times daily (Figure 1). ${ }^{13}$ If pharmacologic prophylaxis was not possible on admission because of bleeding risk or active bleeding, mechanical prevention with an IPC device was applied. The pharmacologic agent was commenced when bleeding risk was minimized within $72 \mathrm{~h}$ of admission. The IPC was discontinued for patients with moderate- to high-risk group but continued in the highest-risk group. VTE prevention measures were continued in the hospital until the patient was ambulatory. After major orthopedic surgery, prevention continued up to 35 days after surgery. Prophylaxis was used during the entire hospital stay in chronically immobilized patients but was discontinued upon discharge to home or to a nursing home. $^{11}$

\section{Bleeding Risk Assessment}

Bleeding risk was assessed before pharmacologic VTE prophylaxis began. A patient was considered at high risk for bleeding if there was evidence of active bleeding, severe traumatic brain injuries with intracerebral hemorrhage, or high-grade intraabdominal solid organ injuries (grade II or above according to the American Association for the Surgery of Trauma injury scoring scales); if there was a history or current evidence of heparin-induced thrombocytopenia; or if the platelet count was $<50,000 / \mathrm{mm}^{3}$ (Figure 1) ${ }^{13}$

\section{VTE Treatment}

Patients with diagnosed DVT and/or PE received therapeutic anticoagulation with enoxaparin $(1 \mathrm{mg} / \mathrm{kg}$ body weight twice daily) or UFH infusion (initial bolus of 80 units $/ \mathrm{kg}$ followed by 18 units $/ \mathrm{kg} / \mathrm{h}$ [grade $2 \mathrm{C}$ ]). ${ }^{11}$ After the patient was able to take oral medications, enoxaparin or UFH was converted to an oral anticoagulant, such as apixaban $10 \mathrm{mg}$ twice daily for 1 week and then $5 \mathrm{mg}$ twice daily for a total of 3 months after the diagnosis (grade 2B). ${ }^{14}$ Additional evaluation and treatment were decided by the treating physician in the outpatient department. Thrombolytic therapy was considered for the PE with hypotension (grade 2B). ${ }^{14}$

\section{Data Collection, Instruments Used, and Measurements}

All patients who met the inclusion criteria had the first mandatory ultrasound of lower limbs within $48 \mathrm{~h}$ of admission to identify any early DVT evidence. The next follow-up ultrasound of the lower limbs occurred after 1 week. Subsequent follow-up ultrasounds were performed if there was clinical suspicion of DVT such as limb swelling, fever, or tenderness, during the hospital stays. CT angiogram of the chest was performed to diagnose and confirm PE on the basis of clinical suspicion and bedside investigation findings. PE was suspected in the case of unexplained hypotension, sudden respiratory deterioration requiring mechanical ventilation, a sudden requirement of high ventilatory settings, hypoxia in arterial blood gas, changes in a chest radiograph, high D-dimer, ECG changes, or right ventricular dilatation on echocardiogram. The patients who were diagnosed with PE had an additional lower-limb ultrasound to rule out the development of an associated DVT, irrespective of clinical signs. Patients who tested positive for DVTs did not undergo routine CT chest angiograms unless clinical signs and symptoms of PE developed, because these patients were already on therapeutic anticoagulation as a treatment for VTE.

We measured data related to demographics, age, gender, nationality, mechanism of injury, baseline characteristics on presentation to the emergency department, associated risk factors, comorbidities, surgeries, injury severity score (ISS), ICU admissions, length of hospital stay, VTE risk score and category, VTE incidence, deaths and DVT prophylaxis used. All data were extracted by a single investigator using a detailed chart review and were verified by a second investigator using the chart review methodology described by Gilbert et al. ${ }^{15}$

The primary goal was to determine the incidence and nature of lower-limb DVT (above or below the knee) in patients with polytrauma. The secondary aim was to report VTE-associated complications, such as PE or death. A VTE-related death was defined as a death caused by confirmed PE with or without pre-existing DVT. Deaths related to injury or complications other than PE, such as coagulopathy, acute respiratory distress syndrome, multiorgan failure, or septicemia, were excluded. 


\section{Statistical Analysis}

The data were subgrouped by VTE risk into a moderate- to high-risk group and a highest-risk group. Demographics, mechanism of injury, baseline injury characteristics on admission, associated risk factors, comorbidities, surgeries, ICU admission, ISS, duration of hospital stay, VTE incidence, and deaths were compared between the two subgroups. The continuous and normally distributed data were summarized using means (and standard deviations [SD]) and were compared using Student's $t$-test. Skewed and ordinal data (eg, Glasgow Coma Scale) were summarized using medians (interquartile ranges [IQRs]) and were compared using the nonparametric MannWhitney $U$-test. Countable data were summarized using proportions (\%) and were compared using the nonparametric chi-squared test. A $p$ value of $<0.05$ was considered significant.

\section{Ethics}

The experiment protocol for involving human data followed national/international/institutional guidelines and the Declaration of Helsinki. The study was approved by the institutional review board of King Saud Medical City (reference number: H1RI-03-Oct18-03). Informed consent from the patient or legal guardian was obtained for study participation.

\section{Results}

We recruited 169 patients who underwent lower-extremity Doppler ultrasound on admission and at 1 week and who were observed until hospital discharge. Most patients were young (mean age, 38.1 years), were male $(88.2 \%)$, and had sustained blunt trauma $(96.5 \%)$; these characteristics are consistent with the demographics of trauma patients in Saudi Arabia. Sixty-nine patients (40.8\%) were considered at the highest-risk for VTE development.

The highest-risk group had a statistically significantly lower coma scale (median, 15 vs $10 ; \mathrm{p}=0.002$ ), higher heart rate (mean, 92.4 vs $99 \mathrm{bpm} ; \mathrm{p}=0.013$ ), lower hemoglobin level (mean, 11.9 vs $10.9 \mathrm{~g} / \mathrm{dL} ; \mathrm{p}=0.007$ ), and more frequent red cell transfusion $(10 \%$ vs $27.5 \%$ of patients; $p=0.003)$. The highest-risk group of patients also had significantly higher ISS $(\mathrm{p}<0.000)$, greater rates of ICU admission ( $41 \%$ vs $66.7 \% ; p=0.001)$, and more extended hospital stays ( 20.8 vs 33.2 days; $p=0.000$ ) than the moderate- to high-risk group. A total of 92 patients (54.4\%) required single or multiple surgeries. Of these, 85 patients $(92.4 \%)$ began prophylaxis preoperatively, and seven patients $(7.6 \%)$ began prophylaxis postoperatively because they required immediate surgery for damage control. In the entire cohort, 32 patients $(18.9 \%)$ had lowerextremity fractures. A total of 22 patients (13\%) received 35 days of prophylaxis from the day of major orthopedic and pelvic surgeries. Some patients presented with comorbidities: 16 patients $(9.5 \%)$ had hypertension, 12 (7.1\%) had diabetes, and six (3.6\%) had ischemic heart disease. Patients who had a history of ischemic heart disease were receiving antiplatelet therapy, and at discharge no extended prophylaxis beyond their regular chronic medications (including antiplatelet therapy) was prescribed for these patients. No patients had a history of oral contraceptive use, a history of prior DVT and/or PE, or a family history of VTE before admission. The demographics, age, gender, nationality, mechanism of injuries, baseline characteristics on presentation to the emergency department, associated risk factors, comorbidities, surgeries, ISS, ICU admission, hospital length of stay, VTE incidence, and deaths for the moderate- to high-risk and the highest-risk groups are listed in Table 1.

A total of 115 patients $(68 \%, 95 \% \mathrm{CI}=0.61-0.75)$ received pharmacologic agents for VTE prophylaxis; 54 patients $(32 \%, 95 \% \mathrm{CI}=0.25-0.39)$ underwent IPC on admission (Table 2). The mean durations of use for a pharmacologic agent and IPC prophylaxis were 25.9 days (SD, 22.3 days) and 14.7 days (SD, 11.2 days), respectively. A total of seven VTE events $(4.2 \%, 95 \% \mathrm{CI}$ $=0.02-0.08)$ were reported. Only three events $(1.8 \%, 95 \%$ $\mathrm{CI}=0.00-0.05)$ were detected by DVT; of these, one occurred in a patient in the moderate- to high-risk group, and two occurred in patients at the highest-risk for DVT development. All patients who were positive for DVT received pharmacologic prophylaxis. All patients with DVT events were asymptomatic on admission and at 1 week. One patient was symptomatic on day 21 , and DVT was confirmed by lower-limb Doppler ultrasound. Two instances of DVT occurred above the knee, and one patient presented with DVT both above and below the knee. There were no additional diagnoses of DVT at hospital discharge. Four patients $(2.4 \%, 95 \% \mathrm{CI}=0.01-0.06)$ were diagnosed with PE during the index presentation. All PE occurrences were diagnosed between 3 and 13 days after injury. Early DVT was not detected in any of the patients with a diagnosed PE. No bleeding events were reported in this series. The characteristics of patients who tested positive for DVT and PE are described in Table 3. In this cohort, 
Table I The Demographics, Mechanism of Injuries, Baseline Characteristics on Presentation to the Emergency Department, Associated Risk Factors, Comorbidities, Surgeries, ISS, ICU Admission, Hospital Length of Stay, VTE Incidence, and Deaths for the Moderate- to High-Risk and the Highest-Risk Groups

\begin{tabular}{|c|c|c|c|c|}
\hline Variables & Total $(n=169)$ & $\begin{array}{l}\text { Moderate- to High Risk for } \\
\text { VTE }(n=100)\end{array}$ & $\begin{array}{l}\text { The Highest-Risk for } \\
\text { VTE }(n=69)\end{array}$ & p-value \\
\hline Age (mean years, SD) & $38.1(14.7)$ & $34.7(10.9)$ & $42.9(17.8)$ & $\mathrm{p}=0.000 *$ \\
\hline $\begin{array}{l}\text { Sex } \\
\qquad \text { Male sex (\%) } \\
\text { Female sex (\%) }\end{array}$ & $\begin{array}{l}149(88.2 \%) \\
20(11.8 \%)\end{array}$ & $\begin{array}{l}88(88 \%) \\
12(12 \%)\end{array}$ & $\begin{array}{l}61(88.4 \%) \\
8(11.6 \%)\end{array}$ & $p=0.936$ \\
\hline $\begin{array}{l}\text { Nationality: } \\
\text { Saudi (\%) } \\
\text { Non-Saudi (\%) }\end{array}$ & $\begin{array}{l}101(59.8 \%) \\
68(40.2 \%)\end{array}$ & $\begin{array}{l}55(55 \%) \\
45(45 \%)\end{array}$ & $\begin{array}{l}46(66.7 \%) \\
23(33.3 \%)\end{array}$ & $\mathrm{P}=0.128$ \\
\hline $\begin{array}{l}\text { Mechanism of injury: } \\
\text { Motor vehicle accident (\%) } \\
\text { Low fall (<Imeter, \%) } \\
\text { High fall (>I meter, \%) } \\
\text { Assault (\%) } \\
\text { Penetrating (\%) }\end{array}$ & $\begin{array}{l}146(86.4 \%) \\
3(1.8 \%) \\
12(7.1 \%) \\
2(1.2 \%) \\
6(3.5 \%)\end{array}$ & $\begin{array}{l}85(85 \%) \\
2(2 \%) \\
7(7 \%) \\
1(1 \%) \\
5(5 \%)\end{array}$ & $\begin{array}{l}6 \mathrm{I}(88.3 \%) \\
\mathrm{I}(1.5 \%) \\
5(7.2 \%) \\
\mathrm{I}(1.5 \%) \\
\mathrm{I}(1.5 \%)\end{array}$ & $\mathrm{P}=0.800$ \\
\hline GCS (median, IQR) & $14(8-15)$ & $15(9-15)$ & $10(7-15)$ & $p=0.002 *$ \\
\hline SBP (mean mmHg, SD) & II $9.5(20.5)$ & $119.3(18.4)$ & II $19.8(23.8)$ & $\mathrm{p}=0.43 \mathrm{I}$ \\
\hline HR (mean beat/min) & $95.1(19)$ & $92.4(18.8)$ & 99 (18.7) & $p=0.013^{*}$ \\
\hline Shock Index (HR/SBP) & $1.2(5.0)$ & $\mathrm{I} .4(6.5)$ & $0.9(0.3)$ & $\mathrm{p}=0.242$ \\
\hline Hemoglobin (mean g/dL, SD) & II.5 (2.5) & $11.9(2.3)$ & $10.9(2.7)$ & $\mathrm{p}=0.007^{*}$ \\
\hline Lactate (mean mmol/L, SD) & $2.6(1.6)$ & $2.5(1.4)$ & $2.8(1.9)$ & $p=0.136$ \\
\hline INR (mean, SD) & I.I (0.2) & $1.03(0.23)$ & $1.09(0.24)$ & $p=0.089$ \\
\hline $\mathrm{PH}$ (mean, SD) & $7.35(0.08)$ & $7.36(0.08)$ & $7.34(0.09)$ & $p=0.112$ \\
\hline $\mathrm{HCO} 3$ (mean, SD) & $21.8(3.7)$ & $22.1(3.2)$ & $21.3(4.3)$ & $p=0.096$ \\
\hline Base deficit (mean, SD) & $-1.9(3.5)$ & $-1.8(3.6)$ & $-2.1(3.4)$ & $p=0.273$ \\
\hline Red cell transfusion in ED (\%) & $29(17.2 \%)$ & $10(10 \%)$ & 19 (27.5\%) & $\mathrm{p}=0.003^{*}$ \\
\hline Intubated (\%) & $78(46.2 \%)$ & 39 (39\%) & $39(56.5)$ & $\mathrm{p}=0.025^{*}$ \\
\hline BMI >24 (\%) & $29(17.2 \%)$ & $13(13 \%)$ & $16(23.2 \%)$ & $\mathrm{p}=0.084$ \\
\hline History of antiplatelet therapy (\%) & $6(3.6 \%)$ & $2(2 \%)$ & $4(5.8 \%)$ & $P=0.190$ \\
\hline Comorbidities: & & & & \\
\hline Hypertension (\%) & $16(9.5 \%)$ & $10(10 \%)$ & $6(8.7 \%)$ & $\mathrm{p}=0.775$ \\
\hline Diabetes (\%) & $12(7.1 \%)$ & $6(6 \%)$ & $6(8.7 \%)$ & $\mathrm{p}=0.502$ \\
\hline Ischemic heart disease (\%) & $6(3.6 \%)$ & $2(2 \%)$ & $4(5.8 \%)$ & $p=0.190$ \\
\hline Previous stroke (\%) & 0 & 0 & 0 & Invalid \\
\hline Cancer (\%) & 0 & 0 & 0 & Invalid \\
\hline $\begin{array}{l}\text { Surgeries: } \\
\quad \text { Number of patients (\%) }\end{array}$ & $92(54.4 \%)$ & $49((49 \%)$ & $43(62.3 \%)$ & $p=0.087$ \\
\hline
\end{tabular}

(Continued) 
Table I (Continued).

\begin{tabular}{|c|c|c|c|c|}
\hline Variables & Total $(n=169)$ & $\begin{array}{l}\text { Moderate- to High Risk for } \\
\text { VTE }(n=100)\end{array}$ & $\begin{array}{l}\text { The Highest-Risk for } \\
\text { VTE }(n=69)\end{array}$ & p-value \\
\hline \multicolumn{5}{|l|}{ Types of surgeries ${ }^{\dagger}:$} \\
\hline Craniotomy/Craniectomy (\%) & 15 (8.9\%) & $8(8 \%)$ & 7 (10.1\%) & $\mathrm{p}=0.232$ \\
\hline Facial (\%) & 14 (8.3\%) & $8(8 \%)$ & $6(8.7 \%)$ & $p=0.872$ \\
\hline Neck exploration (\%) & I (0.6\%) & I (I\%) & $0(0 \%)$ & Invalid \\
\hline Thoracotomy (\%) & $5(3 \%)$ & $3(3 \%)$ & $2(2.9 \%)$ & $p=0.969$ \\
\hline Laparotomy (\%) & $13(7.7 \%)$ & $6(6 \%)$ & $7(10.1 \%)$ & $p=0.320$ \\
\hline Vascular (\%) & $4(2.4 \%)$ & $2(2 \%)$ & $2(2.9 \%)$ & $P=0.706$ \\
\hline Pelvic fixation (\%) & $8(4.7 \%)$ & $3(3 \%)$ & $5(7.2 \%)$ & $\mathrm{p}=0.20 \mathrm{I}$ \\
\hline Upper limb (\%) & $16(9.5 \%)$ & $10(10 \%)$ & $6(8.7 \%)$ & $p=0.776$ \\
\hline Lower limb (\%) & $32(18.9 \%)$ & $16(16 \%)$ & $16(23.2 \%)$ & $\mathrm{p}=0.24 \mathrm{I}$ \\
\hline Vertebral Column (\%) & $19(11.2 \%)$ & $9(9 \%)$ & $10(14.5 \%)$ & $\mathrm{P}=0.267$ \\
\hline ISS: & & & & $\mathrm{P}<0.000 *$ \\
\hline$<16(\%)$ & $76(45 \%)$ & $54(54 \%)$ & 22 (31.9\%) & \\
\hline $16-25(\%)$ & $62(36.7 \%)$ & $40(40 \%)$ & $22(31.9 \%)$ & \\
\hline$>25$ (\%) & $31(18.3 \%)$ & $6(6 \%)$ & $25(36.2 \%)$ & \\
\hline ICU admissions (\%) & $87(51.5 \%)$ & $4 I(4 I \%)$ & $46(66.7 \%)$ & $\mathrm{P}=0.00 \mathrm{I} *$ \\
\hline $\begin{array}{l}\text { Hospital length of stay (mean } \\
\text { days, SD) }\end{array}$ & $25.9(22.3)$ & $20.8(18.2)$ & $33.2(25.5)$ & $\mathrm{P}=0.000 *$ \\
\hline VTE (\%): & 7 (4.2\%) & $2(2 \%)$ & 5 (7.2\%) & $\mathrm{p}=0.092$ \\
\hline DVT (\%) & 3 (1.8\%) & I (I\%) & 2 (2.9\%) & $\mathrm{p}=0.358$ \\
\hline PE (\%) & $4(2.4 \%)$ & I (I\%) & $3(4.3 \%)$ & $\mathrm{p}=0.159$ \\
\hline Death $^{\ddagger}(\%)$ & $9(5.33 \%)$ & $4(4 \%)$ & $5(7.2 \%)$ & $p=0.356$ \\
\hline
\end{tabular}

Notes: *Significant $\mathrm{p}$-values, ${ }^{\dagger}$ Same patient had single or multiple surgeries. ${ }^{\ddagger}$ No deaths were related to VTE.

Abbreviations: ISS, injury severity score; ICU, intensive care unit; VTE, venous thromboembolism; SD, standard deviation; GCS, Glasgow coma scale; IQR, interquartile range; SBP, systolic blood pressure; HR, heart rate; INR, international normalized ratio; BMI, body mass index; DVT, deep vein thrombosis; PE, pulmonary embolism.

Table 2 VTE Prophylaxis on Admission

\begin{tabular}{|c|c|c|c|c|}
\hline VTE Prophylaxis & $\begin{array}{l}\text { Total } \\
(n=169)\end{array}$ & $\begin{array}{l}\text { Moderate- to High-Risk for } \\
\text { VTE }(n=100)\end{array}$ & $\begin{array}{l}\text { The Highest-Risk for } \\
\text { VTE }(n=69)\end{array}$ & p-value \\
\hline $\begin{array}{l}\text { Pharmacological agents } \\
\left(\text { Enoxaparin }^{\dagger} \text { or } \mathrm{UFH}^{\ddagger}\right)\end{array}$ & II 5 (68\%) & 72 (72\%) & $43(62.3 \%)$ & \multirow[t]{2}{*}{$\begin{array}{l}\mathrm{P}=0.185 \\
\text { (Chi-squared } \mathrm{I.76})\end{array}$} \\
\hline IPC* & $54(32 \%)$ & $28(28 \%)$ & 26 (37.7\%) & \\
\hline
\end{tabular}

Notes: ${ }^{\dagger}$ Enoxaparin: Patients with moderate- to high-risk received enoxaparin $40 \mathrm{mg}$ subcutaneously daily. Patients in the highest-risk group received enoxaparin doses of $30 \mathrm{mg}$ twice daily in addition to IPC. ҒUFH: When the patient's creatinine clearance was $<30 \mathrm{~mL} / \mathrm{min}$ or when enoxaparin was contraindicated (eg, pregnancy), the patient received $5000 \mathrm{IU}$ of UFH subcutaneously three times daily in both groups. *IPC: If pharmacologic prophylaxis was not possible on admission because of bleeding risk or active bleeding. The pharmacologic agent was commenced when bleeding risk was minimized within $72 \mathrm{~h}$ of admission. The IPC was discontinued for patients with moderate- to high-risk group but continued in the highest-risk group.

Abbreviations: VTE, venous thromboembolism; UFH, unfractionated heparin; IPC, intermittent pneumatic compressor.

nine patients (5.33\%) died, but no in-hospital deaths were related to DVT or PE.

\section{Discussion}

The optimal approach to VTE prophylaxis in patients with trauma remains ill defined. To our knowledge, no level-1 evidence or randomized, controlled trial on this topic exists to date. ${ }^{11,14}$ Moreover, the risk stratification of patients with trauma and single or multiple injuries is extremely difficult. LMWH, such as enoxaparin, has remained a standard of care for VTE prophylaxis for more than a decade. LMWH has shown better efficacy and equal or even better safety than 
Table 3 Characteristics of Positive DVT and PE Patients

\begin{tabular}{|c|c|c|c|c|c|c|c|c|c|}
\hline $\begin{array}{l}\text { Sl. } \\
\text { No. }\end{array}$ & Patient & $\begin{array}{l}\text { Risk } \\
\text { Category }\end{array}$ & ICU & ISS & $\begin{array}{l}\text { Extremities } \\
\text { Fractures }\end{array}$ & Associated Injuries & $\begin{array}{l}\text { Site \& } \\
\text { Type of } \\
\text { DVT }\end{array}$ & $\begin{array}{l}\text { Associated } \\
\text { DVT and/or } \\
\text { PE }\end{array}$ & $\begin{array}{l}\text { Day of } \\
\text { Diagnosis }\end{array}$ \\
\hline 1 & DVT & $\begin{array}{l}\text { Moderate- } \\
\text { to High }\end{array}$ & Yes & 17 & $\begin{array}{l}\text { Right tib/fib } \\
\text { fractures }\end{array}$ & $\begin{array}{l}\text { Severe TBI, C2 fracture, and } \\
\text { bilateral lung contusions }\end{array}$ & $\begin{array}{l}\text { Right above } \\
\text { knee } \\
\text { (occlusive) }\end{array}$ & No PE & 7 \\
\hline 2 & DVT & Highest & Yes & 38 & $\begin{array}{l}\text { Right tib/fib } \\
\text { fractures }\end{array}$ & $\begin{array}{l}\text { Severe TBI, bilateral lung } \\
\text { contusions and haemothoraces }\end{array}$ & $\begin{array}{l}\text { Left above } \\
\text { and below } \\
\text { knee } \\
\text { (occlusive) }\end{array}$ & No PE & 7 \\
\hline 3 & DVT & Highest & Yes & 27 & No & Severe TBI and facial fractures & $\begin{array}{l}\text { Bilateral } \\
\text { above Knee } \\
\text { (non- } \\
\text { occlusive) }\end{array}$ & No PE & 21 \\
\hline 4 & PE & $\begin{array}{l}\text { Moderate- } \\
\text { to High }\end{array}$ & Yes & 17 & No & $\begin{array}{l}\text { Severe TBI, facial fractures, } \\
\text { Bilateral lung contusions, and T6- } \\
\text { I I fractures }\end{array}$ & $\begin{array}{l}\text { Bilateral } \\
\text { segmental }\end{array}$ & No DVT & 9 \\
\hline 5 & PE & $\begin{array}{l}\text { Moderate- } \\
\text { to High }\end{array}$ & No & 22 & Left femur & $\begin{array}{l}\text { Bilateral lung contusions, multiple } \\
\text { rib fractures, and LI-4 fractures }\end{array}$ & $\begin{array}{l}\text { Bilateral } \\
\text { lobar and } \\
\text { segmental }\end{array}$ & No DVT & 3 \\
\hline 6 & PE & Highest & Yes & 33 & No & $\begin{array}{l}\text { TBI, facial fractures, bilateral lung } \\
\text { contusions, right } 3 \text { rd rib fracture, } \\
\text { and LI compression fracture }\end{array}$ & $\begin{array}{l}\text { Right } \\
\text { segmental }\end{array}$ & No DVT & 5 \\
\hline 7 & PE & Highest & Yes & 26 & No & $\begin{array}{l}\text { Facial fractures, left } \\
\text { hemopneumothorax, left pubic } \\
\text { rami fractures. }\end{array}$ & $\begin{array}{l}\text { Bilateral } \\
\text { segmental }\end{array}$ & No DVT & 13 \\
\hline
\end{tabular}

Abbreviations: DVT, deep vein thrombosis; PE, pulmonary embolism; ICU, intensive care unit; ISS, injury severity score; TBI, traumatic brain injuries; C2, second cervical vertebra; T6-II, sixth to eleventh thoracic vertebrae; LI-4, first to fourth lumbar vertebrae; LI, first lumbar vertebra.

UFH. ${ }^{16}$ Meta-analyses have also confirmed a higher benefit and risk ratio for LMWH than for UFH as a VTE prophylaxis. ${ }^{16}$ LMWH is associated with a 10 times lower incidence of heparin-induced thrombocytopenia compared with UFH. Bleeding is even less frequent with prophylactic LMWH. Even in renal impairment, LMWH has demonstrated a higher efficacy and safety ratio than UFH. ${ }^{16}$ A study by Geerts et $\mathrm{al}^{17}$ has shown that LMWH is more effective than UFH in patients with trauma to prevent VTE. Although the ACCP guidelines do not recommend using an IVC filter as VTE prevention (grade 2C), some authorities support its use in high-risk patients when neither pharmacologic nor mechanical prophylaxis is feasible. $^{11,18}$

IPC was used on admission in 54 patients (32\%). Subsequently, all patients received pharmacologic prophylaxis and/or IPC, according to the risk assessment categories, within $72 \mathrm{~h}$. Current studies and guidelines support starting pharmacologic prophylaxis even earlier. The recommendation is to start LMWH within 36-72 h of admission in conjunction with neurosurgical consultation for traumatic brain injury. ${ }^{19,20}$ In patients with abdominal solidorgan injuries, the introduction of LMWH within $48 \mathrm{~h}$ in the absence of ongoing bleeding appears safe. ${ }^{19,20}$

Currently, no consensus exists for routine screening of DVT or VTE in asymptomatic patients. ${ }^{11}$ The ACCP guidelines do not recommend periodic surveillance DVT with Doppler ultrasound for high-risk or critically ill patients after trauma (grade 2C). ${ }^{11}$ However, according to the Eastern Association for the Surgery of Trauma, some high-risk patients may benefit from routine screening for DVT. ${ }^{21}$ DVT screening for asymptomatic patients is often debated among surgeons, and clinical importance remains unclear. $^{22}$ Some older studies have found it clinically beneficial. ${ }^{22}$ Recently, one group has shown that PE rates in patients with trauma decreased with routine surveillance and early management of DVT. ${ }^{23}$ Others suggest that 
routine surveillance for DVT in the presence of appropriate VTE prophylaxis is not effective at preventing clinically relevant VTE, so the increased cost of medical testing is not warranted. Furthermore, routine surveillance may incur risks associated with anticoagulation treatment for clinically irrelevant DVT and/or PE treatment. ${ }^{24}$

The incidence of VTE remained low (1.8\% for DVT, $2.4 \%$ for PE, and $4.2 \%$ overall) in this study compared with other studies because of the policy-driven application of early thromboprophylaxis and satisfactory compliance. A systematic review reported that patients with trauma who received no prophylaxis had an overall VTE incidence of $12 \%$, and those who received only mechanical prophylaxis had a $7 \%$ incidence. ${ }^{25}$ Other studies reported incidences of VTE after trauma of $4.6-28 \%$ with prophylaxis $^{26-28}$ and up to $90 \%$ without prophylaxis. ${ }^{29,30}$ Geerts et $\mathrm{al}^{29}$ reported that DVT incidence in 349 patients with trauma was $58 \%$; these cases were diagnosed by venography 1-3 weeks after admission, and patients received no prophylaxis. A recent Cochrane database review of 16 studies and 3005 patients concluded that prophylaxis reduced the risk of VTE (mechanical: risk ratio [RR], 0.43 [95\% CI, 0.25-0.73]; pharmacologic: RR, 0.48 [95\% CI, 0.25-0.95]; both approaches: RR, 0.34 [95\% CI, 0.19-0.60]). ${ }^{25}$

None of the patients in this study with PE had DVT. A weak association exists between the incidence of DVT and PE. PE in trauma is difficult to predict and is not associated with traditional risk factors. Studies have shown that patients with trauma who develop PE may not have evidence of lower-extremity thrombosis. ${ }^{24,31-34}$ Whether the risk factors for PE differ from those associated with DVT in injured patients is not well studied. Independent risk factors for DVT in trauma include a delay of $>48 \mathrm{H}$ in prophylaxis after injury. Conversely, independent risk factors for $\mathrm{PE}$ include male gender and serum lactate level $>5 \mathrm{mmol} / \mathrm{L}^{33,34}$ Some studies have suggested that early PEs identified on imaging may result from severe chest trauma rather than an actual thromboembolic event. ${ }^{35,36}$ Another study showed that long bone fractures, admission to the general ward, and female gender were associated with early PE $(<96 \mathrm{~h}) .{ }^{37}$ Major surgery within $48 \mathrm{~h}$ and severe brain and chest injury have been related to delayed PE. ${ }^{35-37}$

The small cohort of patients was a limitation of this study. The study included consecutive patients during the study period from the most active trauma center in the country. However, the study would have had more strength if baseline data about the incidence of DVT and/or PE (nonfatal and fatal) were known before the risk assessment tool was used. Polytrauma often induces coagulopathy. ${ }^{38}$ Trauma-induced coagulopathy remains one of the most diagnostically and therapeutically challenging conditions. Elevated D-dimer is also common after acute trauma. ${ }^{39}$ Therefore, levels of fibrinogen and D-dimer as baseline investigations would have been beneficial to this study. Although only 169 patients with polytrauma underwent Doppler ultrasound, we attempted to develop a model to improve the patient outcomes after trauma.

\section{Conclusions}

The incidence of DVT in patients with polytrauma remained low in this small series. Reasons include the mandatory VTE risk assessment for all hospitalized patients and the early initiation of prophylaxis. DVT events despite prophylaxis reflect questions about the preventability of post-injury DVT. Diagnosis of PE in patients with trauma depends on a high index of clinical suspicion and the presence of clinical signs or symptoms, even in the absence of DVT. Traditional anticoagulation and/or mechanical prevention may not be adequate to prevent VTE in injured patients. Consideration should be given to more innovative options (eg, low-dose apixaban). We also recommend using a trauma center registry to measure DVT and PE incidence regularly to improve trauma care quality.

\section{Disclosure}

The authors declare no conflicts of interest for this work.

\section{References}

1. Cushman M, Tsai AW, White RH, et al. Deep vein thrombosis and pulmonary embolism in two cohorts: the longitudinal investigation of thromboembolism etiology. Am J Med. 2004;117(1):19-25. doi:10.1016/j.amjmed.2004.01.018

2. Oger E. Incidence of venous thromboembolism: a community-based study in Western France. EPI-GETBP Study Group. Groupe d'Etude de la Thrombose de Bretagne Occidentale. Thromb Haemost. 2000;83 (5):657-660. doi:10.1055/s-0037-1613887

3. Knudson MM, Ikossi DG, Khaw L, Morabito D, Speetzen LS. Thromboembolism after trauma: an analysis of 1602 episodes from the American college of surgeons national trauma data bank. Ann Surg. 2004;240(3):490-498. doi:10.1097/01.sla.0000137138.40116.6c

4. Sevitt S, Gallagher N. Venous thrombosis and pulmonary embolism. A clinico-pathological study in injured and burned patients. Br J Surg. 1961;48(211):475-489. doi:10.1002/bjs. 18004821103

5. Fitts WT Jr, Lehr HB, Bitner RL, Spelman JW. An analysis of 950 fatal injuries. Surgery. 1964;56:663-668.

6. Freeark RJ, Boswick J, Fardin R. Posttraumatic venous thrombosis. Arch Surg. 1967;95(4):567-575. doi:10.1001/archsurg.1967.01330160037005 
7. Kitagawa K, Sakoda S. Mechanism underlying thrombus formation in cerebral infarction. Rinsho Shinkeigaku. 2009;49(11):798-800. doi:10.5692/clinicalneurol.49.798

8. Hak DJ. Prevention of venous thromboembolism in trauma and long bone fractures. Curr Opin Pulm Med. 2001;7(5):338-343. doi:10.1097/00063198-200109000-00015

9. Brill JB, Badiee J, Zander AL, et al. The rate of deep vein thrombosis doubles in trauma patients with hypercoagulable thromboelastography. J Trauma Acute Care Surg. 2017;83 (3):413-419. doi:10.1097/TA.0000000000001618

10. Engelman DT, Gabram SG, Allen L, Ens GE, Jacobs LM. Hypercoagulability following multiple trauma. World J Surg. 1996;20(1):5-10. doi:10.1007/s002689900001

11. Guyatt GH, Akl EA, Crowther M, et al. Executive summary: antithrombotic therapy and prevention of thrombosis, 9th ed: American college of chest physicians evidence-based clinical practice guidelines. Chest. 2012;141(2 Suppl):7S-47S. doi:10.1378/ chest.1412S3

12. Chowdhury S, Bahatheq S, Alkaraawi A, et al. Surgical site infections after trauma laparotomy. An observational study from a major trauma center in Saudi Arabia. Saudi Med J. 2019;40(3):266-270. doi:10.15537/smj.2019.3.24005

13. Al-Hameed FM, Al-Dorzi HM, Abdelaal MA, et al. The Saudi clinical practice guideline for the prophylaxis of venous thromboembolism in medical and critically ill patients. Saudi Med J. 2016;37 (11):1279-1293. doi:10.15537/smj.2016.11.15268

14. Kearon C, Akl EA, Ornelas J, et al. Antithrombotic therapy for VTE disease: CHEST guideline and expert panel report [published correction appears in Chest. 2016 Oct;150(4):988]. Chest. 2016;149 (2):315-352. doi:10.1016/j.chest.2015.11.026

15. Gilbert EH, Lowenstein SR, Koziol-McLain J, Barta DC, Steiner J. Chart reviews in emergency medicine research: where are the methods? Ann Emerg Med. 1996;27(3):305-308. doi:10.1016/ s0196-0644(96)70264-0

16. Mismetti P, Laporte S, Darmon JY, Buchmüller A, Decousus H. Meta-analysis of low molecular weight heparin in the prevention of venous thromboembolism in general surgery. Br J Surg. 2001;88 (7):913-930. doi:10.1046/j.0007-1323.2001.01800.x

17. Geerts WH, Jay RM, Code KI, et al. A comparison of low-dose heparin with low-molecular-weight heparin as prophylaxis against venous thromboembolism after major trauma. $N$ Engl J Med. 1996;335(10):701-707. doi:10.1056/NEJM199609053351003

18. DeYoung E, Minocha J. Inferior vena cava filters: guidelines, best practice, and expanding indications. Semin Intervent Radiol. 2016;33 (2):65-70. doi:10.1055/s-0036-1581088

19. Shahan CP, Magnotti LJ, McBeth PB, Weinberg JA, Croce MA, Fabian TC. Early antithrombotic therapy is safe and effective in patients with blunt cerebrovascular injury and solid organ injury or traumatic brain injury. J Trauma Acute Care Surg. 2016;81 (1):173-177. doi:10.1097/TA.0000000000001058

20. Rappold JF, Sheppard FR, Carmichael SP II, et al. Venous thromboembolism prophylaxis in the trauma intensive care unit: an American association for the surgery of trauma critical care committee clinical consensus document. Trauma Surg Acute Care Open. 2021;6(1):e000643. doi:10.1136/tsaco-2020-000643

21. Rogers FB, Cipolle MD, Velmahos G, Rozycki G, Luchette FA. Practice management guidelines for the prevention of venous thromboembolism in trauma patients: the EAST practice management guidelines work group. $J$ Trauma. 2002;53(1):142-164. doi:10.1097/00005373-200207000-00032

22. Haut ER, Schneider EB, Patel A, et al. Duplex ultrasound screening for deep vein thrombosis in asymptomatic trauma patients: a survey of individual trauma surgeon opinions and current trauma center practices. $J$ Trauma. 2011;70(1):27-34. doi:10.1097/ TA.0b013e3182077d55
23. Allen CJ, Murray CR, Meizoso JP, et al. Surveillance and early management of deep vein thrombosis decreases rate of pulmonary embolism in high-risk trauma patients. J Am Coll Surg. 2016;222 (1):65-72. doi:10.1016/j.jamcollsurg.2015.10.014

24. Cipolle MD, Wojcik R, Seislove E, Wasser TE, Pasquale MD. The role of surveillance duplex scanning in preventing venous thromboembolism in trauma patients. $J$ Trauma. 2002;52(3):453-462. doi:10.1097/00005373-200203000-00007

25. Barrera LM, Perel P, Ker K, Cirocchi R, Farinella E, Morales Uribe $\mathrm{CH}$. Thromboprophylaxis for trauma patients. Cochrane Database Syst Rev. 2013;(3):CD008303. doi:10.1002/14651858. CD008303.pub2

26. Lu JP, Knudson MM, Bir N, Kallet R, Atkinson K. Fondaparinux for prevention of venous thromboembolism in high-risk trauma patients: a Pilot Study. J Am Coll Surg. 2009;209(5):589-594. doi:10.1016/j. jamcollsurg.2009.08.001

27. Velmahos GC, Kern J, Chan LS, Oder D, Murray JA, Shekelle P. Prevention of venous thromboembolism after injury: an evidence-based report--part II: analysis of risk factors and evaluation of the role of vena caval filters. J Trauma. 2000;49(1):140-144. doi:10.1097/00005373-200007000-00021

28. Thorson CM, Ryan ML, Van Haren RM, et al. Venous thromboembolism after trauma: a never event? Crit Care Med. 2012;40 (11):2967-2973. doi:10.1097/CCM.0b013e31825bcb60

29. Geerts WH, Code KI, Jay RM, Chen E, Szalai JP. A prospective study of venous thromboembolism after major trauma. $N$ Engl J Med. 1994;331(24):1601-1606. doi:10.1056/NEJM199412153312401

30. Shackford SR, Davis JW, Hollingsworth-Fridlund P, Brewer NS, Hoyt DB, Mackersie RC. Venous thromboembolism in patients with major trauma. Am J Surg. 1990;159(4):365-369. doi:10.1016/s00029610(05)81272-3

31. Shuster R, Mathew J, Olaussen A, et al. Variables associated with pulmonary thromboembolism in injured patients: a systematic review. Injury. 2018;49(1):1-7. doi:10.1016/j.injury.2017.08.024

32. Tadlock MD, Chouliaras K, Kennedy M, et al. The origin of fatal pulmonary emboli: a postmortem analysis of 500 deaths from pulmonary embolism in trauma, surgical, and medical patients. Am J Surg. 2015;209(6):959-968. doi:10.1016/j.amjsurg.2014.09.027

33. Brakenridge SC, Henley SS, Kashner TM, et al. Comparing clinical predictors of deep venous thrombosis versus pulmonary embolus after severe injury: a new paradigm for posttraumatic venous thromboembolism? J Trauma Acute Care Surg. 2013;74 (5):1231-1238. doi:10.1097/TA.0b013e31828cc9a0

34. Brakenridge SC, Toomay SM, Sheng JL, Gentilello LM, Shafi S. Predictors of early versus late timing of pulmonary embolus after traumatic injury. Am J Surg. 2011;201(2):209-215. doi:10.1016/j. amjsurg.2009.12.005

35. Spencer Netto F, Tien $\mathrm{H}, \mathrm{Ng}$ J, et al. Pulmonary emboli after blunt trauma: timing, clinical characteristics and natural history. Injury. 2012;43(9):1502-1506. doi:10.1016/j.injury.2010.12.028

36. Gelbard RB, Karamanos E, Farhoomand A, et al. Immediate post-traumatic pulmonary embolism is not associated with right ventricular dysfunction. Am J Surg. 2016;212(4):769-774. doi:10.1016/j. amjsurg.2015.08.027

37. Menaker J, Stein DM, Scalea TM. Incidence of early pulmonary embolism after injury. J Trauma. 2007;63(3):620-624. doi:10.1097/ TA.0b013e31812f60aa

38. Giordano S, Spiezia L, Campello E, Simioni P. The current understanding of trauma-induced coagulopathy (TIC): a focused review on pathophysiology. Intern Emerg Med. 2017;12(7):981-991. doi:10.1007/s11739-017-1674-0

39. Zhang LD, Liu HB, Li YN, Ma HM, Liu YB, Wang MY. Correlation analysis between plasma D-dimer levels and orthopedic trauma severity. Chin Med J (Engl). 2012;125(17):3133-3136. 


\section{Publish your work in this journal}

Vascular Health and Risk Management is an international, peerreviewed journal of therapeutics and risk management, focusing on concise rapid reporting of clinical studies on the processes involved in the maintenance of vascular health; the monitoring, prevention and treatment of vascular disease and its sequelae; and the involvement

of metabolic disorders, particularly diabetes. This journal is indexed on PubMed Central and MedLine. The manuscript management system is completely online and includes a very quick and fair peerreview system, which is all easy to use. Visit http://www.dovepress. com/testimonials.php to read real quotes from published authors.

Submit your manuscript here: https:/www.dovepress.com/vascular-health-and-risk-management-journal 